\title{
EUGENESIA Y DETERMINISMO GENÉTICO. UNA SOLUCIÓN SIMPLE A UN PROBLEMA COMPLEJO
}

\author{
Fabiola Villela Cortés ${ }^{1}$
}

Resumen: Los objetivos de este artículo son, primero, exponer el estado del arte de la eugenesia, cómo se desarrolló en el siglo $\mathrm{XX}$, cómo es la nueva eugenesia y cuáles son las dos posturas ético-filosóficas actuales (bioconservadores y transhumanistas). En segundo lugar, sostener que existe un determinismo genético operante en ambos discursos, lo que provoca que el discurso eugenésico actual está siendo utilizado para proponer soluciones simples (genéticas) a problemas complejos (conductuales o sociales). El tercero y último objetivo es cuestionar las motivaciones que subyacen a la implementación de la nueva eugenesia.

Palabras clave: eugenesia, determinismo genético, transhumanistas, bioconservadores

\section{Eugenics and genetic determinism. A simple solution for a complex problem}

\begin{abstract}
The main goals of this article are first, to present the current situation of eugenics, how it developed during the XX century, the main characteristics of the "new eugenics" and the two current ethical-philosophical postures (bioconservatives and transhumanist). Second, to sustain the existence of genetic determinism in both postures, provoking the actual eugenic discourse is being use to propose simple solutions (genetic ones) to complex problems (conducts or social). Third and last, is to question the motivations laying in the implementation of the new eugenics.
\end{abstract}

Key words: eugenics, genetic determinism, transhumanist, bioconservatives

\section{Eugenia e determinismo genético. Uma soluçáo simples para um problema complexo}

Resumo: Os objetivos deste artigo são, em primeiro lugar, expor o estado da arte da eugenia, como se desenvolveu no século $\mathrm{XX}$, como é a nova eugenia e quais são as duas posiçôes ético-filosóficas atuais (bioconservadora e transumanista). Em segundo lugar, argumentar que não há um determinismo genético operante em ambos os discursos, o que faz com que o discurso eugênico atual esteja sendo usado para propor soluçóes simples (genéticas) para problemas complexos (comportamentais ou sociais). Em terceiro e último é questionar quais são as motivaçốes que subjazem a implementação da nova Eugenia.

Palavras-chave: eugenia, determinismo genético, transumanistas, bioconservadores

\footnotetext{
${ }^{1}$ Programa Universitario de Bioética de la Universidad Nacional Autónoma de México, México.

Correspondencia: fabiola.villela@gmail.com
} 


\section{Introducción}

\section{La vieja eugenesia}

La idea de mejorarnos nos ha acompañado a lo largo de nuestra historia. Los antiguos griegos, romanos e indios, mantuvieron prácticas enfocadas en la mejora de las altas elites de sus pobladores, por medio de la selección de pareja, aborto, infanticidio, educación, etc.(1).

Fue Sir Francis Galton, en 1883, el que le dio carácter de ciencia al uso de prácticas sistemáticas que tenían como fin mejorar la especie humana. Fue así como el movimiento eugenésico surgió en Inglaterra, continuando su camino por Europa hasta llegar a América, primero a Estados Unidos (EUA) y posteriormente a México, Brasil, Perú, Chile y Argentina $(1,2)$.

En todos los países en los que durante el siglo XX se llevó a cabo un movimiento eugenésico, apoyado y liderado por el gobierno, se desarrollaba un proceso histórico común: acelerada industrialización, urbanización e inmigración, tres características que provocaron la inconformidad de las clases medias, pues veían en los inmigrantes extranjeros y los campesinos pobres que migraban a las ciudades una amenaza para el orden social; por tanto, al encontrar en la eugenesia una alternativa científica y biológica para resolver estos problemas, dieron su apoyo a los pequeños grupos de elite que introdujeron los movimientos eugenésicos en sus países.

De forma generalizada, las medidas negativas de la eugenesia, como la segregación sexual y racial, restricciones de inmigración (principalmente en EUA y Alemania), prohibición legal de matrimonios "interraciales" y esterilización involuntaria, estaban destinadas a las clases bajas, con el objetivo último de "desaparecerlas"; mientras que las medidas positivas estaban enfocadas a mejorar la clase media y alta de las sociedades, permitiendo su auge, favoreciendo la unión entre jóvenes idóneos para la sociedad y para patrocinar el matrimonio de la joven pareja con la esperanza de que procrearían hijos sanos, dotados de las cualidades consideradas adecuadas $(2,3)$.

La idea de "eugenesia" que predomina en este pe- riodo es la denominada totalitaria; esto es, realizada por Estados con gobiernos que ejercieron un poder centralizado y autoritario. El movimiento eugenésico de la Alemania nazi fue el más poderoso y cruel de todos.

Al finalizar la Segunda Guerra Mundial se dio a conocer el alcance que tuvo la eugenesia en la Alemania nazi, dejando al mundo perplejo e indignado frente a los atropellos cometidos contra miles de personas en pos del perfeccionamiento humano, y fue en este punto de la historia donde se pensó que la eugenesia pasaría como uno de los capítulos más tristes, violentos y deshumanizantes, convirtiéndose en tabú. Pocos años después, la eugenesia parecía haber quedado únicamente en los libros de historia, debido a la asociación generalizada con el Tercer Reich.

\section{La nueva genética}

La segunda mitad del siglo XX traería consigo muchos cambios. En 1953 se marcó un hito en la historia de la biología al darse a conocer la estructura del ADN; posteriormente, la teoría de la biología sintética cambiaría nuestra concepción de herencia y, poco a poco, comenzaron los estudios enfocados en conocer el genoma de plantas, animales y humanos, su interacción con el ambiente y las posibilidades de modificarlo exitosamente. La década de los sesenta trajo consigo debates en torno a la autonomía reproductiva y al control natal. En la década de los setenta se vivió el debate sobre el aborto, las posturas provida y proelección, y fue así como, poco a poco, el tema de la eugenesia encontró nuevamente cabida a partir de las diferentes técnicas en reproducción asistida, las nuevas tecnologías en la fertilización in vitro, la amniocentesis, los bancos de semen, la ingeniería genética y finalmente la clonación.

Actualmente existe cierto recelo académico en utilizar el término "eugenesia", por la asociación que tiene con el asesinato de miles de personas que no cumplían con el modelo de "raza superior"; se piensa que debería reemplazarse por "intervenciones genéticas", "perfeccionamiento genético" o "ingeniería genética”. Sin embargo, en palabras de Ekberg(4): 
"...despite significant procedural, legislative and administrative differences between the old eugenics and the new genetics, and despite significant spatial, temporal and cultural variations in interpretation and implementation, at the ideological level, there is essentially no difference. The old eugenics was genet$i c s$ and the new genetics is eugenics".

En la actualidad, la eugenesia positiva consiste en la aplicación del conocimiento biológico molecular, el diagnóstico y la intervención genética en la búsqueda del enriquecimiento de nuestro genotipo para modificar nuestro fenotipo, con la finalidad de obtener una descendencia que la selección natural probablemente nunca hubiera conseguido; mientras que la eugenesia negativa busca corregir errores genéticos y eliminar enfermedades o factores genéticos desencadenantes de ellas.

Esta nueva eugenesia tiene como objetivo mejorar o perfeccionar la especie humana, siempre y cuando ésta sea individual, no coercitiva y libre del Estado. El mecanismo de regulación estará determinado por intereses económicos del mercado.

Queda claro que uno de los aspectos de imoralidad de la vieja eugenesia fue su carácter impositivo que perseguía fines estatales, el cual radicó en la eliminación de grupos considerados no deseables (grupos raciales - como los negros o mestizos - , étnicos — judíos, indios- o sociales —alcohólicos, criminales o prostitutas-) (2). Independientemente de cómo queramos denominarlos, ambos buscan lo mismo: modificarnos — a nosotros mismos o a nuestra descendenciapara mejorarnos.

\section{¿Mejorar a quiénes, cómo y con qué fin?}

¿Mejorar a quienes? A todos aquellos que así lo deseen, esa es la propuesta de la denominada eugenesia liberal, término acuñado por Nicolas Agar en 1999. De acuerdo con Michael Freeden(5), esta nueva propuesta permite a cualquiera que lo desee, por la razón que sea, ofrecer servicios genéticos a todos aquellos que lo anhelen y estén dispuestos a aceptarlos en los términos que se ofrecen. Una de las principales características que tiene este nuevo tipo de eugenesia es que la línea entre tratamiento y mejora se desvanece, ampliando el rango de decisión de los padres de elegir las características que consideren más convenientes para sus hijos.

¿Cómo? Mediante técnicas de ingeniería genética, basadas la gran mayoría en tratamientos de fertilización asistida con transferencia de embriones, mapeo genético, diagnóstico genético preimplantatorio y prenatal, o quizá mediante la inserción de un cromosoma extra ${ }^{2}$. Todas estas técnicas estarían encaminadas a seleccionar óvulos, espermatozoides, mitocondrias, embriones e información genética deseable, para asegurar que el hijo por nacer pueda hacerlo sin taras, enfermedades o defectos congénitos, o bien con la carga genética diseñada exprofeso por sus progenitores.

¿Con qué fin? La respuesta a esta pregunta es controversial y dependerá de la postura que adoptemos o analicemos para poder evaluarla, ya sea que nos sintamos afiliados a una postura conservadora (denominada "bioconservadora") o a una mucho más liberal denominada "transhumanista".

\section{Transhumanistas y bioconservadores}

Los transhumanistas como Nick Bostrom $(6,7)$, Gregory Stock(8) y Maxwell Mellman(9), entre otros, creen que estas tecnologías deberían estar ampliamente disponibles; los individuos deberían poder decidir cuáles de estas tecnologías aplicar a sí mismos o a su descendencia(7). La finalidad es superar las barreras de nuestra condición humana y dar un salto evolutivo hacia seres poshumanos, con mayor inteligencia, fuerza física, mejor carácter y más longevos que nosotros, los seres humanos actuales.

En el otro extremo se encuentran los bioconservadores, quienes se oponen al uso de esta tecnología y solo estarían dispuestos a aceptarla si su uso se mantiene estrictamente restringido al ámbito de la salud, pues parten del supuesto de que la aplicación de estas tecnologías sin restricciones, en pos del perfeccionamiento, socavarían la dignidad humana(7). Sostienen que la finalidad de estas intervenciones no es justificable, pues diseñar un hijo restringe la libertad y autonomía que él mismo pueda tener en su vida, y proponen prohibir el uso de tecnologías que podrían mejorarnos. En este grupo encontramos a Leon $\operatorname{Kass}(10,11)$,

${ }^{2}$ Para mayor información ver http://2045.com/news/31813.html 
Francis Fukuyama(12) y Michael Sandel(13).

\section{Critica a los transuhumanistas y a los bioconserva- dores}

Ambos grupos sostienen que las intervenciones genéticas traerán consigo consideraciones éticas, tanto para nosotros como para los seres poshumanos, mas no coinciden en los mismos problemas.

Los transhumanistas apuestan a que, tarde o temprano, se podrán identificar los genes que intervienen en el talento, el carácter o la creatividad, y que, cuando eso suceda, quienes tengan la posibilidad de pagarlo podrán alterar o diseñar el código genético de sus hijos por nacer, porque los padres tendrían la libertad y el interés de brindarles a sus descendientes las mejores herramientas. Las consecuencias que prevén desde la ética en este escenario son mínimas, pues no ven un problema en la justificación de este tipo de intervenciones, ya que las equiparan a prácticas actuales, como pagar las mejores escuelas, contratar entrenadores deportivos, usar suplementos vitamínicos o la vacunación, e incluso prácticas un poco más agresivas, como el uso de Ritalin para mejorar la concentración o el tratamiento con la hormona del crecimiento para ganar un aproximado de 10 centímetros de altura(13).

Aquellos que están en contra de esta postura sostienen que no es equiparable la selección de la escuela al uso de Ritalin (para mejorar la concentración) y mucho menos al diseño genético. Sin embargo, los argumentos, a favor y en contra, rara vez entran en diálogo, porque unos apelan a la sacralidad de la naturaleza humana, los otros a los beneficios tecnológicos y a las innumerables capacidades que se pueden adquirir por medio de las modificaciones genéticas. Donde unos sienten temor, los otros sienten esperanza. De ahí que los transhumanistas, como Julian Savulescu(14), Nick Bostrom(6,7) o Gregory Stock(8), lejos de contra argumentar o debatir sobre estas objeciones, centradas en razones deontológicas o religiosas, insisten en que estas intervenciones son para quien esté en capacidad de hacerlo, si los demás no están de acuerdo, pueden no hacer uso de ellas.

Ahora bien, la crítica es que, a diferencia de su predecesora, la nueva eugenesia estará regulada por los mecanismos económicos del mercado, lo que genera dos problemas evidentes: por un lado, la libertad de obtener los beneficios de estas nuevas tecnologías estaría al alcance de quienes pudieran pagarlas, y, por el otro, se corre el riesgo de que los productos, objetivos y resultados de la investigación se vean corrompidos por intereses de las compañías que desarrollan y aplican las nuevas biotecnologías, con el poder de poner a su favor cualquier regulación sanitaria o de biose$\operatorname{guridad}(15)$.

Por su parte los bioconservadores parten del supuesto de que las intervenciones genéticas provocarán la pérdida de la dignidad humana (Leon Kass), el Factor X (Francis Fukuyama), nuestra libertad (Jürgen Habermass) (16) o nuestros "dones" (Michael Sandel), no en nosotros sino en los individuos producto de estas intervenciones. Frente a este punto hay dos grandes objeciones: la primera es pensar que son los seres humanos actuales los que pueden decidir sobre quién tiene o no dignidad humana, libertad o un don de ahora en adelante. Un problema similar surgió poco después que nació Louise Brown, también conocida como "la primera bebé de probeta". Muchos pensaron que le iba a faltar ese toque humano y la realidad es que la mujer es indistinguible de cualquier otra mujer en el mundo, actualmente tiene 39 años, está casada y es madre de dos hijos, simplemente su origen fue distinto a lo considerado normal en 1978.

"A pesar del alboroto que causó su nacimiento, (Louise Brown) señaló que su vida había sido convencional (...). El nacimiento de niños concebidos 'in vitro' dejó de ser noticia hace tiempo. Reino Unido ha registrado el nacimiento de 10.242 niños engendrados por esta técnica, según los datos disponibles a finales de marzo de 2004 por la Autoridad de Fertilidad Humana y Embriología” (17).

La segunda es lo engañoso del discurso. Es la pérdida de control lo que, a mi parecer, subyace a la postura bioconservadora. Argumentar que nosotros somos los que vamos a ver la pérdida de eso que a nosotros sí nos hace plenamente humanos y a ellos no, es colocarnos en una posición de poder y control, y lo preocupante es perder dicha posi- 
ción. Supongamos que el sueño transhumanista se realiza y en los próximos 100 años vemos el surgimiento de seres claramente poshumanos, mejores que nosotros en todos los sentidos. Eso a nosotros ¿en qué nos convierte? ¿En subhumanos, en seres no tan evolucionados? Si respondemos que sí, entonces no nos cuesta trabajo apreciar la posición vulnerable en la que vamos a encontrarnos, y sabemos, porque así lo hemos permitido, que frente a esta situación los que tienen la ventaja, el poder y el control son los que se perciban como mejores. Ejemplos de estos abundan en nuestra historia. Siempre ha habido personas categorizadas como subhumanos, y esto se ve con mayor claridad en las crónicas de los conquistadores y pioneros de los nuevos mundos que colonizaron los europeos en los inicios de la Modernidad. Al lugar al que llegaban había individuos que se parecían a ellos, sí, pero no eran propiamente humanos, según la interpretación que predominó en los colonizadores. Los nativos se asemejaban a animales o a niños, y sus vidas no eran igualmente valiosas que las de los conquistadores; por tanto, podían ser tratados como objetos, propiedades fácilmente adquiribles y posiblemente desechables.

Resulta fácil imaginar, entonces, que este podría ser el futuro que nos aguarda. Este temor se ha plasmado claramente en la película ${ }^{3}$ Star Trek. En la oscuridad (2013), en el que Khan, interpretado por el actor británico Benedict Cumberbatch, un superhombre genéticamente modificado que fue despertado después de casi 300 años de animación suspendida, busca, entre otras cosas, eliminar a los humanos por considerarlos inferiores. De igual forma, la película Gattaca. Experimento genético nos muestra un futuro en el que los No Válidos o "hijos de Dios" son, en su mayoría, seres humanos nacidos de forma natural, cuyos padres dejaron al azar su carga genética y con ello su futuro, cuya única labor es cubrir las necesidades de los Válidos o humanos, diseñados genéticamente. Ambas películas plantean el escenario opuesto al presentado por los bioconservadores, no la pérdida de la dignidad humana sino el temor a ser

\footnotetext{
${ }^{3} \mathrm{Si}$ me permito utilizar obras de ficción para ejemplificar una postura científica es porque, en mis años de investigación, he encontrado que la literatura y el cine, en particular la ciencia ficción, son los únicos sitios en los que se ha ejercitado la reflexión sobre algunas preguntas bioéticas; no a partir de ideales o propuestas, sino como realidades, lo que nos permite cierto tipo de exploración mental sobre algunos de estos problemas.
}

perseguidos o desplazados por la nueva estirpe de humanos.

Este escenario refleja el miedo de continuar con la serie de eventos violentos en los que las sociedades humanas se han organizado históricamente. Una alternativa factible es prever desde ahora un mecanismo que nos permita coexistir. En este sentido, considero oportuno buscar alternativas filosóficas y sociales que nos ayuden a no caer en este escenario en el que se prohiba el mejoramiento genético basándonos en la posible pérdida de la humanidad.

A mi parecer, y pesar de las diferencias significativas entre ambos grupos, ambos comparten terreno común: el determinismo genético.

\section{La respuesta está en nuestros genes}

El determinismo genético es la teoría biológica que sostiene que las características complejas de los seres humanos son causadas por genes específicos(18) y, por tanto, es extremadamente difícil intentar modificar el comportamiento criminal, la obesidad o el alcoholismo por cualquier otro medio que no sea el genético.

Tal como la eugenesia de mediados de siglo XX buscó limitar la inmigración y la reproducción (por medio de la esterilización), y la posterior eliminación, de grupos no deseables, con la intención de erradicar de sus sociedades a los alcohólicos, prostitutas y enfermos mentales, porque se pensaba que estas conductas eran hereditarias ${ }^{4}$, la nueva eugenesia busca relacionar ciertas condiciones conductuales con genes específicos heredables. La ventaja en esta ocasión es que se eliminaría al gen y no al individuo.

El fenómeno que permite el resurgimiento del determinismo genético es considerar nuestro material genético como un icono. Aparentemente no tenemos problemas con procedimientos que modifiquen nuestro corazón, cerebro o hígado, pero recientemente intervenir en el genoma es cuestionable, ya que creemos que la genética es sinónimo de destino(19).

\footnotetext{
${ }^{4}$ Estas acciones tuvieron lugar en EUA y Alemania principalmente. Ambos países promovieron leyes de inmigración, y en EUA se resolvió la esterilización a raíz del caso Bruck vs. Bell.
} 


\section{El ADN como icono}

El ADN se ha convertido en un icono cultural, cuyo sentido simbólico es independiente de su definición biológica, es una forma de definir personalidad, justificar estereotipos y moldear políticas sociales con base en fuerzas naturales. Creemos que nuestro genoma es lo que nos hace humanos. No solo nos da una idea de nuestra salud, sino que, aparentemente, ofrece bases sólidas para las relaciones humanas. Al parecer, nos indica si vamos a ser criminales, alcohólicos, disléxicos, exitosos o inteligentes; por ende, debemos entender, aceptar y adaptarnos a nuestras limitaciones genéticas(19). Donna Haraway(20) sugiere que "el gen" se ha convertido en un fetiche, desarticulado de su contexto y considerado como algo en sí mismo, cargado de significado psicológico, cuando la realidad es que solo es un factor dentro de un complejo entramado de sustancias, reacciones y procesos orgánicos, los cuales actúan en un contexto histórico, social, cultural y ambiental específico.

De acuerdo con Strohman(20), esta interpretación está vinculada con la información dada a conocer por los medios de comunicación que, junto con los intereses de grandes empresas dedicadas al desarrollo de tratamientos genéticos, promueven la idea de que intervenir la información genética es la respuesta a nuestros males.

\section{Medios de comunicación, conflictos de interés y An- gelina Jolie}

Lo cierto es que tenemos que considerar que los medios masivos de comunicación, junto con las afirmaciones de científicos prominentes, propician que el genoma sea representado, según sostiene Nelkin, como un término icónico. ¿Por qué no creerle al Dr. James Watson cuando afirma que "solíamos pensar que nuestro destino estaba en las estrellas. Ahora sabemos (...) que nuestro destino está en nuestros genes?" 5 . Tal como sostiene un participante del estudio de Ann Scott(20), "la gente siempre se ha interesado en la astrología y otras formas de saber el destino. ¿Por qué no tener una forma científica de conocer(lo) en vez de algo que no es científico?". Este tipo de afirmaciones

\footnotetext{
${ }^{5}$ Cita textual: "We used to think that our fate was in our stars, but now
} we know that, in large measure, our fate is in our genes". están teniendo un gran impacto en la sociedad. Se ha elevado la demanda de pruebas genéticas que detectan la presencia de genes asociados a enfermedades, con el objetivo de tomar medidas preventivas.

Por ejemplo, el 14 de mayo de 2013 el diario The New York Times publicó en su apartado de Opinión una carta escrita por la célebre actriz norteamericana Angelina Jolie, en la que se lee que la pérdida de su madre, debida al cáncer de mama, fue el principal motivo para someterse no solo al escaneo genético sino a una doble masectomía, seguida de una reconstrucción mamaria estética(21). Y en marzo de 2015 se sometió nuevamente a una cirugía preventiva de retirada de ovarios y trompas de Falopio, para reducir la posibilidad de padecer cáncer(22).

La razón por la cual esta actriz tomó una decisión que para muchos puede parecer demasiado drástica, fueron los resultados de un estudio genético (para detectar el gen BRCA1) que arrojaban una posibilidad de $87 \%$ de desarrollar cáncer de mama y $50 \%$ de padecer cáncer de ovario. Su decisión ha causado polémica, tanto en los medios de comunicación como en el ámbito médico.

La carta de la actriz señaló en ambas ocasiones que no quiso dejar esta situación en lo privado, porque considera que muchas mujeres se pueden ver beneficiadas de su historia, tanto para realizarse escaneos genéticos como para tomar decisiones que, en su caso, lejos de debilitarla como mujer, la empoderaron $(21,22)$.

En ambas ocasiones, los diarios del mundo replicaron la noticia en diferentes idiomas, unos alabando la fortaleza de esta mujer y otros cuestionando su decisión, la ligereza con la que Jolie presenta los efectos secundarios y el mensaje que se estaba dando a mujeres de todo el mundo.

La principal crítica es que tener la mutación del BRCA1 y BRCA2 no es equivalente a una sentencia de muerte, ni tampoco significa que quien la tenga desarrollará cáncer de mama u ovario: solo es un índice de riesgo. De acuerdo con el Instituto Nacional de Cáncer del gobierno de los EUA, una mujer nacida hoy tendrá una posibilidad de 1 a 8 de ser diagnosticada de cáncer de mama en el 
transcurso de su vida. Se estima que la mutación BRCA1 y BRCA2 está presente en el $5 \%$ a $10 \%$ de los casos de cáncer de mama u ovárico entre las mujeres caucásicas norteamericanas. Por tanto, seguir la recomendación de Jolie "no salvará la vida de innumerables mujeres", pues para la mayoría de ellas existen otros factores de riesgo no hereditarios relacionados con sus hábitos diarios, como el peso, el consumo de alcohol, el tabaquismo o la falta de actividad física(23), que las hacen más propensas a desarrollar cáncer de mama que la presencia de estos genes (BRCA1 y BRCA2).

Me parece interesante presentar el caso, porque en él se puede apreciar la recepción que está teniendo la información genética relacionada con el cáncer de mama por una figura pública que, nos guste o no, tiene gran influencia en los medios. Bertha Coombs, reportera de CNBC, reportó el 14 de mayo de 2013(24) una nota en la que se lee que, a partir de la publicación del caso Jolie, las acciones de Myriar Genetics (empresa encargada de realizar el test genético en busca de los genes BRCA1 y BRCA2, y que hasta poco antes de la noticia tenía la patente por el proceso de detección) habían incrementado un $4 \%$ en cuestión de días. Esta información indica que la consolidación de un mercado enfocado en la búsqueda e identificación de genes que permitan tomar decisiones preventivas (como la de Jolie), o solicitar tratamientos de fertilización in vitro con diagnóstico genético preimplantatorio para traer bebés sanos (como las bebés en España(25) e Inglaterra(26) que nacen "libres del gen" BRCA1 y BRCA2), o generar medicamentos y tratamientos personalizados, etc., es posible.

Lo cierto es que la gran mayoría de los comunicados tienen títulos atractivos, pero parciales, como "El ADN de la agresividad"(27), "Identifican el gen del alcoholismo"(28), o "The lazy gene" (29). Estos artículos comienzan señalando que el "gen para" la agresión, el alcoholismo o la pereza ha sido encontrado, y, salvo que uno se quede leyendo toda la nota, podrá darse cuenta de que, conforme se expone la información, se van haciendo las aclaraciones, como que no es determinante, que se encuentra asociado a otros factores, que únicamente se encontró en población finlandesa, etc. Lamentablemente, ya dieron una idea concreta: cualquier conducta puede ser atribuida a nuestros genes.
Y es precisamente este tipo de información la que parece tergiversar el alcance del conocimiento que tenemos sobre la estructura e interacción de nuestro genoma, tanto intrínsecamente como con el ambiente.

\section{No todo depende de un gen}

Para sostener una idea determinista, primero es necesario comprender las variaciones existentes entre los genes y la expresión de la enfermedad.

Una enfermedad monogenética se entiende como aquella en la que, al realizar un estudio genotípico, la presencia o ausencia de un gen conlleva un 100\% de probabilidad de desarrollar el padecimiento en un lapso de tiempo determinado; incluso, puede que pasen ańos antes de que se expresen los primeros síntomas; de ahí que esta condición también se conozca como presintomática y el ejemplo más famoso es la enfermedad de corea de Huntington.

Por otro lado, están las enfermedades multifactoriales, en las que uno o varios genes se encuentran involucrados en la expresión de un rasgo, pero estos genes pueden reaccionar de forma diferente al ambiente; así, la mutación es necesaria pero no suficiente para determinar la enfermedad, como el cáncer o la fenilcetonuria.

Finalmente, está el enmascaramiento genético, esto es, la persona tiene solo una copia defectuosa del gen, mientras la otra se mantiene "sana". Si esta última compensa el error de la primera, evita que se presente la enfermedad; sin embargo, puede pasar este defecto genético a sus hijos, los cuales podrían presentarla en caso de juntar las dos copias defectuosas, como ocurre en la fibrosis quística(30).

Aunado a lo anterior, existen factores genéticos que debemos considerar: (a) un solo gen puede estar involucrado en la producción de más de una proteína, (b) las funciones genéticas pueden traslaparse, (c) la interacción genética y (d) la expresión de un gen está ligada a otros factores, por ejemplo, la señalización emitida por una hormona puede alterar la expresión genética(31). Por tanto, si pensábamos que las modificaciones genéticas necesarias para que un tratamiento eugenésico sea eficiente eran sencillas, estábamos equivocados. 


\section{Conclusión. Quien tiene un martillo, cree que todos sus problemas son clavos}

He intentado exponer hasta el momento los parámetros de la eugenesia y del determinismo genético para que, a partir de este punto, el argumento de que podemos perfeccionarnos, no solo en lo físico (altura, fuerza, longevidad) sino en lo psicológico (más creativos, menos violentos, más éticos) resulta inválido por una razón: queremos encontrar respuesta simples a problemas complejos. Esto es, querer resolver problemas de orden social y de conducta por medio de la genética es reducir y homogeneizar nuestros problemas para poder aplicarles la solución que hoy está capturando nuestra atención y en la que estamos vertiendo esperanzas de mejora: la genética.

Considero que el debate ético debería centrarse en el por qué y para qué buscamos estas mejoras. Si nos preguntamos: ¿por qué queremos modificarnos con el objetivo de no tener que respirar, no beber agua dulce, o no comer? Y la respuesta es: para dejar de preocuparnos por la contaminación global y encontrar en estas modificaciones una salida de supervivencia a la falta de alimento, de agua potable o de aire limpio, entonces mi posición es que no es ético el uso de estas tecnologías, porque se buscaría una respuesta genética a problemas provocados por una industrialización descontrolada y la generación de desechos químicos tóxicos que se vierten al ambiente.

Si nos preguntamos por qué queremos encontrar la relación genética de comportamientos indeseados socialmente como la violencia, la prostitución o el alcoholismo, y la respuesta es para modificar nuestros genes y dejar de lado los factores sociales que los promueven, como la falta de empleo, el crecimiento de zonas marginales o el aumento de poblaciones vulnerables en cinturones de miseria que caracterizan a las grandes urbes, entonces $\mathrm{mi}$ posición es que no es ético porque estamos buscando una salida de orden genético a un problema social.

Si nos preguntamos por qué queremos eliminar el gen del factor de coagulación sanguínea VIII de mi descendencia y respondemos que para eliminar la probabilidad de que padezcan hemofilia tipo A o sean portadores, y con esto elimino uno de los tantos factores que pueden afectar su calidad de vida, entonces mi postura es que esto es ético, porque estamos buscando una respuesta genética a un problema genético.

Queda mucho por resolver en torno a la eugenesia (o la nueva genética). Que sea accesible es uno de los grandes puntos que aún está pendiente, probablemente porque los que están a favor consideran que no solo es deseable sino ético el uso de estas nuevas tecnologías, incluso si éstas mantienen o incrementan la inequidad social (9) por su parte, los que están en contra poco han dicho al respecto. En este sentido, falta mucha investigación y muchas propuestas para resolver este problema.

El punto clave es pensar que la decisión final la tomarán los individuos y que cada uno podrá elegir el mecanismo que desee, por considerarlo seguro, porque cuenta con la información necesaria para tomar una decisión autónoma y porque considera que las consecuencias serán mayoritariamente benéficas y los riesgos han sido sopesados y medidos. Parto del principio de responsabilidad, no solo de las acciones que nos afectarán a nosotros, sino de aquellas que serán trascendentes para las generaciones futuras.

\footnotetext{
${ }^{6}$ Han determinado que se generarán dos grupos: los gen-ricos y los gen-pobres.
} 


\section{Referencias}

1. Mac-Lean R. La Eugenesia en América Latina. Revista Mexicana de Sociología UNAM 1951; 13(3): 359-387.

2. Kevles D. In the name of eugenics. USA: Harvard University Press; 1985.

3. Caplan AL. When medicine went mad: Bioethics and the Holocaust. USA: Humana Press; 1992.

4. Ekberg M. The old eugenics and the new genetics compared. Soc Hist Med 2007; 20(3): 581-593.

5. Fox D. The Illiberity of "liberal eugenics". Ratio 2007; 20(1): 1-25.

6. Bostrom N. In defense of posthuman dignity. Bioethics 2005; 19(3): 202-214.

7. Bostrom N. The future of humanity. Geopolitics, History, and international relations. 2009; 1(2): 41-78.

8. Stock G. Redesigning Humans, Our inevitable genetic future. EUA: Houghton Mifflin; 2002.

9. Mehlman M. Las tecnologías genéticas y el desafío a la igualdad. En Luna F, Riviera López E. (comp.). Los desafíos éticos de la genética humana. México: UNAM, Instituto de Investigaciones Filosóficas, Fondo de Cultura Económica; 2005: 147-181.

10. Kass L. Beyond Therapy: Biotechnology and the Pursuit of Happiness. Report of the President's Council on Bioethics, which was created by President George W. Bush on November 28, 2001, by means of Executive Order 13237; 2001.

11. Kass L. La sabiduría de la repugnancia. En Luna F, Riviera López E, (comp.). Los desafíos éticos de la genética humana. México: UNAM, Instituto de Investigaciones Filosóficas, Fondo de Cultura Económica; 2005: 181-214.

12. Kevles D. In the name of eugenics. EUA: Harvard University Press; 1985.

13. Fukuyama F. Our posthuman future: consequences of the biothechnology revolution. New York, EUA: Farrar, Straus y Giroux; 2002.

14. Sandel M. Contra la perfección. La ética en la era de la ingeniería genética. Madrid: Marbot Ediciones; 2007.

15. Savulescu, J. 2001. Procreative beneficence: why we should select the best children. Bioethics 2001; 15(5/6): 413-426.

16. O’Lery MM. 2006. Eugenesia actual: un nuevo desafío para las disciplinas metacientíficas. Estudios Fronterizos. Universidad de Baja California 2006; 7(13): 29-42.

17. Habermas J. El futuro de la naturaleza humana ¿hacia una eugenesia liberal? España: Paidos; 2002.

18. Louise Brown, la primera 'nińa probeta', da a luz un niño concebido de forma natural. El País, 2007. Disponible en: http://sociedad.elpais.com/sociedad/2007/01/16/actualidad/1168902003_850215.html

19. Stroham R. Beyond genetic determinism. California Monthly 2001; 24-27. Disponible en: http://www.sbs.utexas.edu/ genetics/literature/cpr/geneticepigenetics-strohman.pdf

20. Nelkin D. Genes: cultural icon. En Encyclopedia of life sciences. John Wiley \& Sons; 2005.

21. Scott A. 'Like editing bits of our selves': geneticisation and human fate. New genetics \& society 2006; 25(1): $109-124$.

22. Jolie A. My Medical Choice. The New York Times. Op-Ed. May 14, 2013. Disponible en http://www.nytimes. com/2013/05/14/opinion/my-medical-choice.html?_r=0

23. Jolie A. Angelina Jolie Pitt: Diary of a Surgery. The New York Times. Op-Ed. March 24, 2015. Disponible en: http:// www.nytimes.com/2015/03/24/opinion/angelina-jolie-pitt-diary-of-a-surgery.html?ref=opinion\&_r=0

24. McCarthy AM, Armstrong K. The Role of Testing for BRCA1 and BRCA2 Mutations in Cancer Prevention. JAMA Internal Medicine 2014; 174(7): 1023-1024.

25. Coombs B. Jolie's Decision Boosts BRCA Test-Maker Myriad. CNBC. 14 May 2013. Disponible en http://www.cnbc. $\mathrm{com} / \mathrm{id} / 100736198$

26. Ferrado M. Nace el primer bebé de España libre del gen que predispone a heredar cáncer de mama. El País. Sociedad, 17 Mar 2011. Disponible en: http://sociedad.elpais.com/sociedad/2011/03/17/actualidad/1300316401_850215.html

27. Batty P. Birth of first british baby screened to be free of cancer gene. The Guardian. Genetics. Jan 9, 2009. Disponible en: https:/www.theguardian.com/science/2009/jan/09/breast-cancer-gene-baby

28. El ADN de la agresividad. El Mundo. 10/06/2012. Disponible en: http://www.elmundo.es/elmundo/2012/06/08/television/1339159039.html

29. Identifican el gen del alcoholismo 20 Minutos. 21.10.2010. Disponible en: http://www.20minutos.es/noticia/849292/0/ identifican/gen/alcoholismo/

30. Petri A. The Lazy Gene. The Washington Post. 10.04.2013. Disponible en: http://www.washingtonpost.com/blogs/compost/wp/2013/04/10/the-lazy-genel

31. Geetter JS. Coding for change: the power of human genome to transform the American health insurance system. American Journal of Law and Medicine 2002; 28(1): 1-76. 
Eugenesia y determinismo genético. Una solución simple a un problema complejo - Fabiola Villela

32. Järviletho T. Behavior: role of genes. Encyclopedia of Life Sciences. John Wiley and Sons; 2006.

33. Agar N. Liberal Eugenics: In defence of human enhancement. Blackwell Publishing; 2004.

34. Agar N. Humanity's End. MIT Press; 2010.

Recibido: 28 de abril de 2016

Aceptado: 1 de junio de 2016 